\title{
Níveis de lisina digestível para poedeiras Hy-Line W-36 em produção
}

\author{
Roberto de Moraes Jardim Filho ${ }^{1}$, José Henrique Stringhini, ${ }^{1,2}$, Maria Auxiliadora Andrade ${ }^{3}$, \\ Marcos Barcellos Café ${ }^{1,2}$, Nadja Susana Mogyca Leandro ${ }^{1,2}$, Fabyola Barros de Carvalho ${ }^{4}$
}

\footnotetext{
1 Programa de Pós-graduação em Ciência Animal - EV/UFG.

2 Departamento de Produção Animal, EV/UFG. Bolsista CNPq.

3 Departamento de Medicina Veterinárial, EVIUFG.

${ }^{4}$ Doutoranda em Zootecnia (UNESP, Botucatu).
}

RESUMO - Objetivou-se determinar os melhores níveis de lisina digestível para poedeiras em produção. Avaliaram-se o desempenho, o consumo de nutrientes, o metabolismo, a qualidade de ovos, os parâmetros sanguíneos e o desenvolvimento do aparelho reprodutor de 160 poedeiras Hy-Line W-36 com 25 semanas de idade. As aves foram distribuídas em delineamento inteiramente casualizado, com quatro níveis de lisina digestível (600, 700, 800 ou $900 \mathrm{mg}$ de lisina/kg de ração) e quatro repetições, utilizando-se o esquema de parcelas subdivididas na avaliação do balanço de nitrogênio, dos parâmetros sanguíneos e do aparelho reprodutor. Os níveis de lisina da dieta influenciaram os consumos de alimento, proteína e energia, cujo ponto de máximo foi observado no nível de 720 mg de lisina. Para produção de ovos, o melhor nível foi 800 mg de lisina; para conversão alimentar, $900 \mathrm{mg}$; e, para balanço de nitrogênio, $700 \mathrm{mg}$. A digestibilidade de extrato etéreo, a qualidade dos ovos, o desenvolvimento do aparelho reprodutor e os parâmetros sanguíneos não foram influenciados pelos níveis de lisina digestível da dieta. Recomendam-se níveis de 700 a 800 mg de lisina digestível para metabolismo e desempenho e 600 mg para qualidade dos ovos e melhor desenvolvimento do aparelho reprodutor.

Palavras-chave: aminoácido, oviduto, produção de ovos, qualidade de ovos, sangue

\section{Levels of digestible lysine for Hy-Line W-36 hens in production period}

\begin{abstract}
In this experiment it was aimed to determine the best levels of digestible lysine for laying hens in production period. Performance, nutrients intake, metabolism, egg quality, blood parameters and development of reproductive tract for 160 Hy-Line W-36 hens at 25 weeks of age. Hens were distributed in a completely randomized design with four levels of digestible lysine $(600,700,800$ or $900 \mathrm{mg}$ of Lys/kg) and four replicates by using a split spot scheme was used at evaluation of nitrogen balance, blood parameters and reproductive tract. Lysine levels in the diet affected food, protein and energy intakes whose maximum point was noted at the level of $720 \mathrm{mg}$ of Lysine. For egg production, food conversion, and nitrogen balance, the best levels of lysine was $800 \mathrm{mg}, 900 \mathrm{mg}$, and $700 \mathrm{mg}$, respectively. The digestibility of ethereal extract, egg quality, development of reproductive tract and blood parameters were not affected by levels of digestible lysine in the diet. It is suggested 700 and $800 \mathrm{mg}$ of digestible lysine for metabolism and performance, respectively, and $600 \mathrm{mg}$ for egg quality and better development of the reproductive trait.
\end{abstract}

Key Words: amino acid, blood, egg production, egg quality, oviduct

\section{Introdução}

A suplementação de aminoácidos essenciais em dietas para poedeiras comerciais e a formulação pelo conceito de proteína ideal vêm ganhando importância no setor produtivo, pois os níveis de aminoácidos, especialmente lisina, variam entre linhagens (Jensen etal., 1974; Klasing, 1998; Al-Saffar \& Rose, 2002; Nahm, 2002). Entretanto, o que causa divergência entre resultados de pesquisas é a diversidade de linhagens (Bustany \& Elwinger, 1987).
Dietas formuladas com adição extra de lisina não melhoram o desempenho nem aumentam o peso de ovos, enquanto dietas à base de proteína resultam em ovos mais pesados (Sohail \& Roland, 1997; Sohail et al., 1999).

No balanceamento de aminoácidos, deve-se averiguar o aproveitamento de nutrientes pelo organismo animal, pois a suplementação de lisina contribui para aumentar os níveis proteicos dietéticos, reduzindo o consumo e a excreção de nitrogênio (Rerat, 1990; Summers, 1993; Meluzzi et al., 2001, Novak et al., 2004).

Recebido em 22/3/2007 e aprovado em 6/4/2009.

Correspondências devem ser enviadas para: henrique@vet.ufg.br 
A maior ingestão de lisina aumenta o peso do ovo e do albume, em decorrência do acréscimo de proteína bruta e de sólidos totais no albume do ovo, mas não influencia o desempenho das aves (Prochaska et al., 1996). Confirmando esses achados, Klasing (1998) explicou que a redução no tamanho do ovo pode estar relacionada à deficiência de um aminoácido e provoca redução no conteúdo do albume.

Ovos comerciais aceitos para consumo in natura devem pesar, no mínimo, $55 \mathrm{~g}$. Para processamento desses ovos, a indústria melhora o conteúdo de gema e de albume e de sólidos totais (Ban, 2002; Faria et al., 2002; American Egg Board, 2006). A ingestão diária de maiores quantidades de lisina pode alterar as concentrações de proteína ou de sólidos totais dos componentes dos ovos (Shafer et al., 1998).

Níveis dietéticos de aminoácidos dietéticos podem alterar a distribuição de nutrientes pela corrente sanguínea e dos níveis de proteína, glicose, creatinina, urato e albumina no plasma. A determinação de proteínas totais plasmáticas, frações albumina e globulina, ácido úrico, enzimas transaminases e creatinina pode expressar interferências metabólicas relacionadas a compostos nitrogenados (Butler, 1971; Cornelius, 1989).

Nesta pesquisa, realizou-se um experimento com o objetivo de avaliar o desempenho e o balanço de nitrogênio e a digestibilidade de extrato etéreo para poedeiras alimentadas com rações com diferentes níveis de lisina digestível. Avaliaram-se ainda a qualidade interna dos ovos, o desenvolvimento do aparelho reprodutor e os parâmetros bioquímicos sanguíneos.

\section{Material e Métodos}

O experimento foi conduzido no Aviário Experimental do Departamento de Produção Animal da Escola de Veterinária - UFG, em Goiânia, Goiás, no período de agosto de 2003 a janeiro de 2004, em um galpão experimental de postura (aberto sem climatização), com quatro fileiras de gaiolas de aço galvanizado, divididas em cinco compartimentos de $40 \times 25 \times 42 \mathrm{~cm}$, cada um de duas aves (densidade de $560 \mathrm{~cm}^{2} /$ ave) com bebedouros nipple e comedouros lineares de alumínio, individualizados por parcela. Utilizaram-se 280 frangas Hy Line W-36 com 25 semanas de idade e peso médio inicial de $1,43 \mathrm{~kg}$ com variação de $10 \%$. O período experimental compreendeu de 25 semanas a 49 semanas de idade e o programa de iluminação foi crescente, com 16 horas de luz no pico de postura, e obtido por meio de lâmpadas incandescentes controlados por relógio automático.

A temperatura do galpão foi obtida diariamente no mesmo horário com termômetro de máxima e mínima (Tabela 1).
Tabela 1 - Temperatura e umidade relativa máxima e mínima durante o período experimental

\begin{tabular}{lccccc}
\hline \multirow{2}{*}{ Mês } & \multicolumn{2}{c}{ Temperatura $\left({ }^{\circ} \mathrm{C}\right)$} & & \multicolumn{2}{c}{ Umidade } \\
\cline { 2 - 3 } \cline { 5 - 6 } & Máxima & Mínima & & Máxima & Mínima \\
\hline Agosto & 31,7 & 11,1 & & 81 & 15 \\
Setembro & 32,4 & 15,7 & & 79 & 12 \\
Outubro & 32,1 & 18,3 & & 96 & 17 \\
Novembro & 30,4 & 19,1 & & 95 & 45 \\
Dezembro & 28,7 & 19,8 & & 97 & 52 \\
Janeiro & 29,1 & 19,9 & & 98 & 57 \\
\hline
\end{tabular}

As dietas experimentais foram formuladas para atender às exigências nutricionais da linhagem na fase de postura (Hy-Line W-36, 2003) e balanceadas de acordo com a composição química e os valores energéticos dos alimentos descritos por Rostagno et al. (2000). Na dieta basal (Tabela 2), o amido foi substituído por 0; 0,128; 0,256 e 0,384\% de $\mathrm{L}$-lisina $\mathrm{HCl}$ para atender aos níveis propostos.

Utilizou-se o delineamento experimental com quatro tratamentos, cada um com quatro repetições de dez aves. Para determinação do balanço de nitrogênio e da digestibilidade de extrato etéreo, 40 aves foram distribuídas no mesmo galpão em quatro tratamentos, cada um com cinco repetições de duas aves. Os tratamentos consistiram de quatro níveis dietéticos de lisina digestível (600, 700, 800

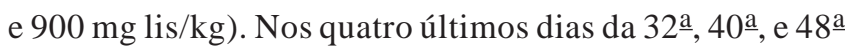
semanas de idade, conduziu-se o ensaio de metabolismo

Tabela 2 - Composição percentual e nutricional das dietas experimentais

\begin{tabular}{lc}
\hline Ingrediente & Dieta basal (kg) \\
\hline Milho & 66,15 \\
Farelo de soja & 17,30 \\
Glutenose & 3,80 \\
Calcário calcítico pedrisco & 2,82 \\
Calcário calcítico fino & 6,60 \\
Fosfato bicálcico & 1,62 \\
Suplemento vitamínico e mineral ${ }^{1}$ & 0,20 \\
Sal comum & 0,40 \\
Dl-metionina 99 & 0,105 \\
L-lisina HCl & 0,000 \\
Amido & 1,000 \\
Composição nutricional calculada & \\
Energia metabolizável (kcal/kg) & 2.800 \\
Proteína bruta (\%) & 15,80 \\
Metionina + cistina digestível (\%) & 0,605 \\
Metionina digestível (\%) & 0,362 \\
Lisina digestível (\%) & 0,606 \\
Cálcio (\%) & 3,960 \\
Fósforo disponível (\%) & 0,392 \\
Sódio (\%) & 0,191 \\
\hline
\end{tabular}

${ }^{1}$ Premix para poedeiras (composição por kg do produto): vit. A - 2.500.000 UI; vit. D3 - 625.000 UI; vit. E - $3.750 \mathrm{mg}$; vit. K3 - $500 \mathrm{mg}$; vit. B1 - $500 \mathrm{mg}$; B2 - 1.000 mg; vit. B6 - 1.000 mg; vit. B12 - 3.750 mcg; niacina - 7.500 mg; ácido pantotênico - $4.000 \mathrm{mg}$; biotina - $15 \mathrm{mg}$; ácido fólico - $125 \mathrm{mg}$; colina $-75.000 \mathrm{mg}$; Se - 45 mg; I - 175 mg; Fe - 12.525 mg; Cu - 2.500 mg; Mn - 19.500 mg; Zn - $13.750 \mathrm{mg}$; avilamicina - $20.000 \mathrm{mg}$. 
pelo método de colheita total de excretas. As excretas foram colhidas duas vezes ao dia, misturadas, homogeneizadas e congeladas $\left(-10^{\circ} \mathrm{C}\right)$ para análise posterior.

O consumo por ave/dia, o consumo de nutrientes (proteína, energia, lisina), a produção de ovos, a conversão alimentar (kg/kg e kg/dúzia de ovos), o peso e a massa de ovo e a relação lisina:massa de ovo foram avaliados a cada 28 dias.

As análises bromatológicas das dietas e das excretas foram realizadas no Laboratório de Nutrição Animal do Departamento de Produção Animal da Escola de Veterinária da UFG (Silva \& Queiroz, 2002). Os níveis de nitrogênio foram determinados pelo método micro-Kjeldahl utilizando-se as seguintes fórmulas para cálculo do balanço de nitrogênio $(\mathrm{BN}): \mathrm{BN}(\mathrm{g})=\mathrm{N}$ Ingerido $-\mathrm{N}$ excretado; $\mathrm{BN}(\%)=(\mathrm{N}$ ingerido $-\mathrm{N}$ excretado $/$ ingerido $\times 100 ; \mathrm{BNM}(\mathrm{mg} / \mathrm{g})=(\mathrm{N}$ Ingerido $-\mathrm{N}$ excretado $\times 1000) /$ massa de ovos. Os níveis de extrato etéreo foram determinados pelo aparelho tipo Goldfisch com éter de petróleo como reagente. As fórmulas para cálculo de digestibilidade do extrato etéreo (DEE) foram: DEE (g) = EE Ingerido-EE excretado; DEE $(\%)=($ E ingerido - E excretado $) /$ ingerido $\times 100 ; \mathrm{DEE}(\mathrm{mg} / \mathrm{g})$ $=($ E Ingerido $-\mathrm{E}$ excretado $\times 1000) /$ massa de ovos .

Para avaliação da qualidade, todos os ovos colhidos nos últimos quatro dias de cada período de 28 dias foram avaliados entre $10 \mathrm{~h}$ e $13 \mathrm{~h}$. Foram avaliados a porcentagem de casca, de gema e de albume; a gravidade específica dos ovos; a unidade Haugh; o índice de gema e a porcentagem de sólidos totais do ovo, da gema e do albume. Para as análises de parâmetros bioquímicos sanguíneos e mensuração do aparelho reprodutor, duas aves foram sacrificadas na 26aㅡ $34^{\underline{a}}$, e $42^{\underline{a}}$ semanas de idade por tratamento para coleta de sangue e mensuração do aparelho reprodutor.

Foram determinados a porcentagem de casca, de gema e de albume, o índice de gema e a unidade Haugh, calculada pela expressão $\mathrm{UH}=100 \mathrm{Log}(\mathrm{h}-1,7 \mathrm{p}+7,6)$, em que $\mathrm{UH}=$ unidade Haugh; $\mathrm{H}$ = altura de albume denso ( $\mathrm{mm}) ; \mathrm{P}=$ peso do ovo (g) (Cotta, 1997). A gravidade específica dos ovos foi determinada nos dois últimos dias de cada período com diferentes soluções salinas e densidades que variaram de 1,060 a 1,100 em intervalos de 0,005. O índice de sólidos totais do ovo, do albume e da gema foi obtido com 16 ovos/ tratamento, que foram quebrados, pesados e colocados em recipientes individuais e colocados em estufa a $65 \pm 5^{\circ} \mathrm{C}$ por 72 horas e, posteriormente, em estufa a $105^{\circ} \mathrm{C}$ por 24 horas, finalizando com a pesagem.

Os valores bioquímicos sanguíneos foram obtidos após 6 horas de jejum, no mesmo horário (13 horas), retirando-se 4,0 mL de sangue por punção intracardíaca de duas aves por tratamento. Parte do sangue foi vertida em frascos contendo anticoagulante (fluoreto de sódio) e centrifugada para obtenção do plasma e a outra foi colocada em repouso em temperatura ambiente para obtenção do soro. As análises foram realizadas no Laboratório Clínico do Departamento de Medicina Veterinária da UFG. Determinaram-se os níveis de glicose plasmática, proteínas totais, albumina, urato e creatinina séricas. Duas aves por tratamento foram sacrificadas para retirada do aparelho reprodutor (ovário e oviduto) e da gordura abdominal.

Os resultados obtidos foram tabulados e analisados por ANOVA (SAS, 2004). A análise de regressão polinomial $(\mathrm{P}<0,05)$ foi adotada para lisina digestível e o teste de Tukey para balanço de nitrogênio e digestibilidade de extrato etéreo, analisado em esquema de parcelas subdivididas e a idade da ave considerada subparcela. Para os parâmetros bioquímicos sanguíneos e aparelho reprodutor, as análises foram realizadas em esquema de parcela subdividida, considerando a idade da ave como subparcela.

\section{Resultados e Discussão}

O nível de lisina digestível, de 800 mg/kg de ração, foi o que promoveu a maior produção de ovos e o de 600 mg/kg, menor produção de ovos (Tabela 3). Ao derivar a equação quadrática, obteve-se ponto máximo de produção no nível de lisina de 799 mg/kg de ração, e consumo estimado de 684,1 mg/ave/dia. Bertechini et al. (1995) observaram efeito linear positivo dos níveis de lisina total $(0,68 ; 0,73 ; 0,78$; 0,83\%) na produção de ovos e recomendaram 789 mg lis/ ave/dia para poedeiras no pico de produção.

Rocha et al. (2009), com intervalos entre 0,545 e 0,770\% de lisina digestível para poedeiras Hy-Line w36 entre 24 e 40 semanas, verificaram efeito linear para porcentagem de postura em poedeiras leves com produção superior a 93,95\% no nível máximo de 0,770\%. Para poedeiras semipesadas, obteve ponto máximo de 0,728\% lisina e 80,8\% de produção. Schutte \& Smink (1998), por sua vez, constataram que níveis de 0,65 a 0,93\% de lisina total para poedeiras de 24 a 36 semanas não influenciaram a produção de ovos. Bouyeh et al. (2002) encontraram maior produção de ovos quando forneceram os níveis de 612 e 544 mg/lis/ ave/dia e demonstraram que, com proteína bruta abaixo do recomendado e acréscimo de lisina, é possível manter o desempenho.

Para os níveis de lisina digestível avaliados neste estudo, houve efeito quadrático $(\mathrm{P}<0,05)$ no consumo por ave/dia (Tabela 3), com ponto máximo de $720 \mathrm{mg} \mathrm{lis/kg} \mathrm{de}$ ração. Gous \& Kleyn (1989) citaram que poedeiras aumentam o consumo quando o nível de qualquer aminoácido essencial é inferior à exigência, o que não 
Tabela 3 - Desempenho de poedeiras alimentadas com rações com diversos níveis de lisina digestível

\begin{tabular}{|c|c|c|c|c|c|c|}
\hline & \multicolumn{4}{|c|}{ Nível de lisina (mg/kg) } & \multirow[t]{2}{*}{$\mathrm{P}^{9}$} & \multirow[t]{2}{*}{$\mathrm{CV}(\%)^{10}$} \\
\hline & 600 & 700 & 800 & 900 & & \\
\hline Produção de ovos $(\%)^{1}$ & 86 & 86 & 88 & 86 & 0,02 & 2,17 \\
\hline Consumo (g/ave/dia) $)^{2}$ & 83,6 & 83,0 & 85,5 & 80,8 & 0,01 & 2,07 \\
\hline Consumo de energia (kcal/ave/dia) ${ }^{3}$ & 239,5 & 236,6 & 244,8 & 230,7 & 0,01 & 2,07 \\
\hline Consumo de proteína (g/ave/dia) ${ }^{4}$ & 13,4 & 13,3 & 13,7 & 12,9 & 0,01 & 2,07 \\
\hline Consumo de lisina (mg/ave/dia) $)^{5}$ & 502,0 & 581,0 & 684,1 & 727,5 & $<0,01$ & 2,17 \\
\hline Conversão alimentar $(\mathrm{kg} / \mathrm{kg})^{6}$ & 1,8 & 1,7 & 1,7 & 1,6 & 0,001 & 1,76 \\
\hline Conversão alimentar (kg/dúzia) ${ }^{7}$ & 1,2 & 1,1 & 1,1 & 1,1 & 0,001 & 1,87 \\
\hline Massa de ovos (g/ave/dia) & 47,2 & 48,7 & 49,3 & 48,5 & 0,07 & 2,07 \\
\hline Relação lisina:massa de ovo $(\mathrm{mg} / \mathrm{g})^{8}$ & 10,6 & 11,9 & 13,9 & 15,0 & $<0,01$ & 1,73 \\
\hline
\end{tabular}

${ }^{1} \mathrm{Y}=11,21+0,191935 \mathrm{X}-0,000120 \mathrm{X}^{2} / \mathrm{R}^{2}=0,98,{ }^{2} \mathrm{Y}=32,6087+0,144397-0,00100254 \mathrm{X}^{2} / \mathrm{R}^{2}=0,52,{ }^{3} \mathrm{Y}=92,9673+0,411677 \mathrm{X}-0,00285825 \mathrm{X}^{2} / \mathrm{R}^{2}=0,52$ ${ }^{4} \mathrm{Y}=5,2164+0,0230993 \mathrm{X}-0,0001600377 \mathrm{X}^{2} / \mathrm{R}^{2}=0,52,{ }^{5} \mathrm{Y}=38,9266+0,779706 \mathrm{X} / \mathrm{R}^{2}=0,98,{ }^{6} \mathrm{Y}=1,95974-0,00031 \mathrm{X} / \mathrm{R}^{2}=0,74,{ }^{7} \mathrm{Y}=1,35423-0,00024535 \mathrm{X} / \mathrm{R}^{2}=$ $0,79,{ }^{8} \mathrm{Y}=1,62142+0,0149854 \mathrm{X} / \mathrm{R}^{2}=0,99,{ }^{9}$ Probabilidade, ${ }^{10}$ Coeficiente de variação

aconteceu neste experimento, pois o consumo foi maior nas aves alimentadas com a ração com $800 \mathrm{mg} / \mathrm{kg} / \mathrm{lisina}$ digestível. Os resultados deste estudo diferem dos apresentados por Chi \& Speers (1977), que, com 0,35 a $0,80 \%$ lisina total para poedeiras às 30 semanas de idade, constataram aumento no consumo das dietas experimentais.

Harms \& Ivey(1993) verificaram consumo de 85,1 g/ave/dia com $0,88 \%$ lisina total para poedeiras comerciais, semelhante ao observado neste experimento. Entretanto, os resultados deste trabalho contradizem os obtidos por Koelkebeck et al. (1991), Bertechini et al. (1995) e Novak \& Scheideler (1998), que não notaram diferenças no consumo ao avaliarem níveis de lisina total para poedeiras comerciais.

Houve efeito linear negativo $(\mathrm{P}<0,05)$ para conversão alimentar (kg/kg e kg/dúzia) (Tabela 3) com o aumento nos níveis de lisina digestível nas dietas. Esses resultados diferem dos encontrados por Aguilera et al. (1990) que encontraram 0,72\% como melhor nível de lisina total para conversão alimentar. No entanto, foram semelhantes aos obtidos por Bertechini et al. (1995) e Goulart (1997), que constataram melhora na conversão alimentar com o aumento dos níveis dietéticos de lisina.

A massa de ovos não diferiu entre os níveis de lisina digestível (Tabela 3 ) e o maior valor numérico $(\mathrm{P}<0,05)$ foi obtido com o nível de $800 \mathrm{mg} / \mathrm{kg}$ lis digestível para aves. Harms \& Ivey (1993) observaram resposta linear negativa da massa de ovos à redução no consumo de lisina. Schutte \& Smink (1998), em experimento com rações com 16,4\% PB para poedeiras leves, indicaram 720 mg lisina digestível/ ave/dia para aumento da massa de ovo. Neste experimento, esse consumo de lisina foi obtido com o nível de $900 \mathrm{mg}$ lisina digestível/kg de ração. Sohail et al. (2002) verificaram que a massa de ovos não foi afetada pelos níveis de 0,65 ; 0,72 e $0,81 \%$ lisina total.
Os níveis de lisina digestível influenciaram $(\mathrm{P}<0,05)$ o consumo de nutrientes (Tabela 3 ), inclusive a quantidade de lisina por grama de massa de ovo produzida. O consumo de nutrientes e de energia é resultado da influência dos níveis dietéticos de lisina. Uzu \& Larbier (1985) realizaram dois experimentos com poedeiras Isa Brown de 20 a 62 semanas de idade no qual avaliaram níveis de proteína e de lisina e observaram que dietas com 13 e 14,5\% PB e 0,58 e 0,65\% de lisina não afetaram os consumos de proteína e de lisina.

Prochaska et al. (1996) avaliaram 0,72; 0,89; 1,15; 1,37\% lisina total para poedeiras Hy Line W-36 e observaram que dietas com $1,37 \%$ lisina total reduziram o consumo desses nutrientes, mas sugeriram que esse nível pode indicar excesso desse aminoácido para aves entre 23 a 38 semanas de idade. Observaram ainda efeito linear positivo do nível e do consumo de lisina, o que também foi verificado neste experimento quando fornecido o nível de $900 \mathrm{mg}$ lisina digestível/kg, no qual as aves consumiram 225 mg mais lisina em comparação àquelas que receberam dieta com $600 \mathrm{mg}$ lisina digestível/kg.

Para a relação lisina:massa de ovo produzida (Tabela 3), houve efeito linear positivo $(\mathrm{P}<0,05)$. Salienta-se, entretanto, que a menor quantidade de lisina fornecida estaria relacionada ao tamanho do ovo produzido, assim como sua qualidade interna (Klasing, 1998; Novak et al., 2004).

Neste estudo, níveis de 700 a $800 \mathrm{mg}$ lis digestível/kg propiciaram $(\mathrm{P}<0,05)$ melhor balanço de nitrogênio na $32^{\mathrm{a}}$ semana (Tabela 4). Nas demais semanas, os níveis de lisina digestível não influenciaram o balanço de nitrogênio, o qual indica a qualidade da proteína, e a proteína de baixa qualidade acarretaria maior excreção de nitrogênio, como resultado da maior desaminação dos aminoácidos (Patrick \& Schaible, 1980). A cadeia de carbono é convertida em ácidos graxos ou carboidratos usados como energia, o que tem custo energético. 
Tabela 4 - Balanço e digestibilidade de nutrientes em poedeiras alimentadas com rações com diversos níveis de lisina digestível

\begin{tabular}{|c|c|c|c|c|c|c|c|}
\hline & \multirow{2}{*}{$\begin{array}{c}\text { Idade } \\
\text { (semanas) }\end{array}$} & \multicolumn{4}{|c|}{ Nível de lisina (mg/kg) } & \multirow[t]{2}{*}{$\mathrm{P}^{10}$} & \multirow[t]{2}{*}{$\mathrm{CV}(\%)^{11}$} \\
\hline & & 600 & 700 & 800 & 900 & & \\
\hline \multirow[t]{3}{*}{ Balanço denitrogênio (g) } & $32^{1}$ & 8,23 & 10,65 & 10,84 & 7,40 & $<0,001$ & 8,38 \\
\hline & 40 & 9,08 & 9,20 & 9,82 & 10,39 & $>0,5$ & 16,98 \\
\hline & 48 & 7,61 & 9,22 & 10,36 & 7,47 & $>0,5$ & 17,22 \\
\hline \multirow[t]{3}{*}{ Balanço denitrogênio (\%) } & $32^{2}$ & 64,50 & 67,21 & 67,89 & 58,93 & 0,002 & 4,76 \\
\hline & 40 & 53,75 & 54,06 & 53,02 & 53,90 & $>0,5$ & 10,22 \\
\hline & 48 & 50,10 & 52,29 & 49,73 & 45,20 & $>0,5$ & 11,01 \\
\hline \multirow[t]{3}{*}{ Balanço doextrato etéreo (g) } & $32^{3}$ & 14,87 & 16,67 & 16,76 & 12,15 & $<0,001$ & 7,27 \\
\hline & $40^{4}$ & 22,96 & 17,62 & 17,69 & 16,66 & 0,013 & 13,10 \\
\hline & $48^{5}$ & 13,60 & 15,36 & 21,75 & 15,40 & 0,004 & 15,82 \\
\hline \multirow[t]{3}{*}{ Digestibilidade do extrato etéreo (\%) } & 32 & 87,89 & 86,85 & 87,97 & 83,75 & 0,09 & 2,80 \\
\hline & $40^{6}$ & 89,74 & 84,95 & 84,89 & 79,64 & $<0,001$ & 2,95 \\
\hline & 48 & 82,80 & 81,94 & 84,86 & 83,84 & $>0,5$ & 3,94 \\
\hline \multirow{3}{*}{$\begin{array}{l}\text { Balanço de nitrogênio / massa } \\
\text { de ovo (mg/g) }\end{array}$} & $32^{7}$ & 20,65 & 25,80 & 26,48 & 18,26 & $<0,001$ & 8,30 \\
\hline & 40 & 22,73 & 23,10 & 23,94 & 26,36 & $>0,5$ & 16,88 \\
\hline & 48 & 20,69 & 24,23 & 26,51 & 19,51 & $>0,5$ & 17,08 \\
\hline \multirow{3}{*}{$\begin{array}{l}\text { Retenção de extrato etéreo / massa } \\
\text { de ovo ( } \mathrm{mg} / \mathrm{g})\end{array}$} & $32^{8}$ & 37,32 & 40,37 & 40,94 & 29,96 & 0,003 & 7,18 \\
\hline & $40^{9}$ & 57,47 & 44,25 & 43,14 & 42,27 & 0,013 & 13,06 \\
\hline & 48 & 37,00 & 40,35 & 55,66 & 40,19 & $>0,5$ & 15,70 \\
\hline
\end{tabular}

${ }^{1} \mathrm{Y}=69,67+0,217711 \mathrm{X}+0,00014662 \mathrm{X}^{2} / \mathrm{R}^{2}=0,99,{ }^{2} \mathrm{Y}=83,74+0,421401 \mathrm{X}+0,0002911617 \mathrm{X}^{2} / \mathrm{R}^{2}=0,94,{ }^{3} \mathrm{Y}=67,09+0,232619 \mathrm{X}+0,000160456 \mathrm{X}^{2} / \mathrm{R}^{2}=0,97$, ${ }^{4} \mathrm{Y}=32,87-0,01885 \mathrm{X} / \mathrm{R}^{2}=0,72,{ }^{5} \mathrm{Y}=-103,8+0,31584 \mathrm{X}-0,000202 \mathrm{X}^{2} / \mathrm{R}^{2}=0,61,{ }^{6} \mathrm{Y}=107,56+0,0304 \mathrm{X} / \mathrm{R}^{2}=0,90,{ }^{7} \mathrm{Y}=156,243+0,495087 \mathrm{X}+$ $0,0003349 \mathrm{X}^{2} / \mathrm{R}^{2}=0,98,{ }^{8} \mathrm{Y}=139,722+0,504859 \mathrm{X}+0,000351 \mathrm{X}^{2} / \mathrm{R}^{2}=0,95,{ }^{9} \mathrm{Y}=81,80+0,0467 \mathrm{X} / \mathrm{R}^{2}=0,71,{ }^{10}$ Probabilidade, ${ }^{11}$ Coeficiente de variação, dados obtidos na base da matéria seca.

Para digestibilidade de extrato etéreo, determinada em grama e em porcentagem (Tabela 4), houve diferença $(\mathrm{P}<0,05)$ em todas as semanas avaliadas. Níveis acima de $780 \mathrm{mg} / \mathrm{kg}$ de lisina digestível influenciaramnegativamente o aproveitamento de extrato etéreo pelo organismo, especialmente na $40^{\mathrm{a}}$ semana de idade. Semelhante ao encontrado neste estudo (776 mg/kg), Aguilera et al. (1990), em experimento com poedeiras comerciais de 44 a 56 semanas de idade, constataram melhor retenção de nitrogênio quando fornecido o nível de 0,725\% lisina.

Os níveis de lisina influenciaram $(\mathrm{P}<0,05)$ o balanço de nitrogênio para massa de ovo somente na 32aㅡ semana (Tabela 4). Já para digestibilidade de extrato etéreo para massa de ovo, houve diferença $(\mathrm{P}<0,05)$ na $32^{\mathrm{a}} \underline{\mathrm{a}}$ e na $40^{\mathrm{a}}$ semana. A derivação da equação de regressão indicou maior gasto de nitrogênio por massa de ovo no nível de $748 \mathrm{mg}$ lisina digestível/kg (Tabela 4). Os níveis de 600 e
900 mg de lisina digestível/kg proporcionaram menor gasto de nitrogênio por grama de massa de ovo produzida. Resultados diferentes foram obtidos por Carvalho (2006), que não encontrou diferença entre os níveis de 700 e 900 mg lisina digestível $/ \mathrm{kg}$. O aumento no nível de lisina digestível reduziu, no entanto, o aproveitamento de extrato etéreo para formação de massa de ovo (Tabela 4).

$\mathrm{O}$ aproveitamento de nitrogênio $(\%)$ diminuiu $(\mathrm{P}<0,05)$ com o avançar da idade da ave (Tabela 5), enquanto a digestibilidade de extrato etéreo (g) foi maior até a 40aㅡ semana de idade (Tabela 5). De acordo com os dados obtidos, o balanço de nitrogênio e a digestibilidade do extrato etéreo foram positivos e em quantidade adequada para as aves. Com o avançar da idade das poedeiras (Tabela 5), ocorreu maior gasto de extrato etéreo por grama de massa do ovo, provavelmente pelo aumento do tamanho do ovo.

Tabela 5 - Balanço de nitrogênio e digestibilidade do extrato etéreo em poedeiras alimentadas com rações com diversos níveis de lisina digestível

\begin{tabular}{|c|c|c|c|c|c|}
\hline & \multicolumn{3}{|c|}{ Semanas } & \multirow[t]{2}{*}{$\mathrm{P}^{1}$} & \multirow[t]{2}{*}{ CV $(\%)^{2}$} \\
\hline & 32 & 40 & 48 & & \\
\hline Balanço de nitrogênio (g) & 9,28 & 9,62 & 8,66 & 0,14 & 14,74 \\
\hline Balanço de nitrogênio (\%) & $64,63 a$ & $53,68 b$ & $49,33 c$ & 0,001 & 8,59 \\
\hline Balanço de extrato etéreo (g) & $15,11 b$ & $18,73 a$ & $16,53 b$ & 0,001 & 12,89 \\
\hline Digestibilidade do extrato etéreo (\%) & $86,61 \mathrm{a}$ & $84,80 \mathrm{ab}$ & $83,36 b$ & 0,007 & 3,25 \\
\hline Balanço de nitrogênio/massa ovo (mg/g) & 22,79 & 24,03 & 22,73 & 0,48 & 14,75 \\
\hline Extrato etéreo/massa (mg/g) & $37,14 b$ & $46,78 a$ & $43,30 a$ & 0,001 & 12,96 \\
\hline
\end{tabular}

${ }^{1}$ Probabilidade. ${ }^{2}$ Coeficiente de variação.

Letras diferentes indicam diferença a 5\% pelo teste Tukey. 
Os níveis de lisina dietética não afetaram $(\mathrm{P}>0,05) \mathrm{o}$ peso do ovo (Tabela 6), o que confirma os resultados obtidos por Flemming et al. (1991) em poedeiras comerciais alimentadas com rações com 0,82; 0,90; 0,95 e 1,00\% lisina total. Bertechini et al. (1995) verificaram resultados similares e não notaram influência dos níveis de 0,680 a 0,830\% lisina total na dieta no peso de ovos de poedeiras comerciais. Scheideler et al. (1996) obtiveram maior peso de ovo quando aumentaram os níveis dietéticos de lisina total. Goulart (1997), por sua vez, recomendou $0,776 \%$ lisina total e consumo médio de $811 \mathrm{mg}$ lisina/ave/dia na dieta de postura.

A relação entre os níveis de lisina e o peso dos ovos pode variar de acordo com a situação (ambiente, linhagem, condições da poedeira, idade). Klasing (1998) relatou que a redução no tamanho do ovo é ocasionada pela deficiência de aminoácido, que reduz o conteúdo de albume. Entretanto, neste estudo não ocorreu diminuição no tamanho do ovo, o que sugere ausência de carências marginais de aminoácidos.

Os percentuais de gema e de albume neste estudo não foram afetados pelos níveis de lisina da dieta (Tabela 6). Conforme Larbier \& Leclercq (1994), a deficiência de lisina pode reduzir o peso da gema, que é rica em lisina. A gema tem cerca de $235 \mathrm{mg}$ de lisina, enquanto o albume, $70 \mathrm{mg}$ de lisina. Scheideler et al. (1996) obtiveram maior percentual de gema com níveis 500, 600, 700, 800, 900 e 1.000 mg lisina/kg. Prochaska et al. (1996), ao fornecerem lisina total nos níveis de $677,1154,1.613 \mathrm{mg} /$ ave/dia para poedeiras de 42 a 64 semanas de idade, verificaram maiores pesos de albume e de gema para aves alimentadas com as rações com nível superior a $1.154 \mathrm{mg} / \mathrm{lisina} / \mathrm{dia}$. Andrade (2004) notou que a suplementação apenas com lisina aumentou a porcentagem de albume apenas quando houve suplementação com outros aminoácidos essenciais.

Em trabalho realizado por Shafer et al. (1996) com 0,70; 1,13 e $1,58 \%$ lisina total em dieta com $13,6 \%$ PB, a suplementação de lisina provocou aumento do peso do albume e do ovo, atribuído ao acréscimo da proteína bruta e dos sólidos totais no albume. Neste estudo, também não houve diferença significativa no peso do ovo e no peso de sólidos totais, o que reforça esses resultados.

Os níveis de lisina utilizados neste estudo não influenciaram $(\mathrm{P}>0,05)$ a unidade Haugh (Tabela 6). Esperava-se que o valor fosse maior para ovos das aves que receberam os maiores níveis de lisina, tendo em vista sua participação desse aminoácido na formação proteica do ovo. Este resultado, no entanto, está de acordo com relatos de Karunajeewa et al. (1987), que não observaram influência dos níveis de 0,7 e 0,8\% lisina total na unidade Haugh. Rocha et al. (2009) também não observaram diferença na qualidade interna em estudo com poedeiras Hy Line W 36 de 24 a 40 semanas de idade alimentadas com rações contendo 0,545 a $0,770 \%$ de lisina digestível. O valor médio encontrado pelos autores foi de 94,42 e 0,4624 para unidade Haugh e índice de gema, respectivamente.

Não houve diferença significativa no conteúdo de sólidos totais da gema, do albume e do ovo (Tabela 6), embora a maior ingestão diária de lisina possa alterar as concentrações de proteína ou de sólidos totais (Shafer et al., 1998). Prochaska et al. (1996), em pesquisa com 677, 1.154 e $1.613 \mathrm{mg}$ lisina total/kg de ração para poedeiras HyLine W-36 entre 42 a 64 semanas de idade, encontraram diferenças para sólidos totais do albume e observaram que o maior índice foi obtido com o nível de $1.613 \mathrm{mg}$ lis total/ kg de ração. Novak et al. (2004), no entanto, encontraram maior conteúdo de sólidos totais no albume em poedeiras arraçoadas com maior nível de lisina. Os resultados encontrados nesta pesquisa para sólidos totais dos componentes do ovo estão de acordo com os obtidos por Rizzo et al. (2004) (Tabela 6), que utilizaram poedeiras Hisex White com 51 semanas de idade e não constataram diferenças no índice de sólidos totais do albume com

Tabela 6 - Características de ovos de poedeiras com diferentes níveis de lisina digestível na dieta

\begin{tabular}{|c|c|c|c|c|c|c|}
\hline & \multicolumn{4}{|c|}{ Nível de lisina (mg/kg) } & \multirow[t]{2}{*}{$\mathrm{P}^{1}$} & \multirow[t]{2}{*}{$\mathrm{CV}(\%)^{2}$} \\
\hline & 600 & 700 & 800 & 900 & & \\
\hline Peso do ovo (g) & 56,8 & 56,6 & 56,1 & 56,3 & $>0,5$ & 1,143 \\
\hline Percentagem de gema & 25,4 & 25,4 & 25,9 & 25,5 & $>0,5$ & 2,307 \\
\hline Percentagem de albume & 62,4 & 62,5 & 61,9 & 62,7 & $>0,5$ & 0,92 \\
\hline Índice de gema & 0,396 & 0,392 & 0,394 & 0,393 & $>0,5$ & 1,703 \\
\hline Unidade Haugh & 101,4 & 102,4 & 101,8 & 101,8 & $>0,5$ & 1,636 \\
\hline Sólidos totais gema (\%) & 60,7 & 60,9 & 60,9 & 61,1 & $>0,5$ & 0,935 \\
\hline Sólidos totais albume (\%) & 13,1 & 13,0 & 12,9 & 12,9 & $>0,5$ & 2,448 \\
\hline Sólidos totais ovo (\%) & 26,2 & 25,8 & 26,6 & 26,2 & 0,35 & 2,324 \\
\hline Percentagem de casca (úmida) & 12,2 & 12,0 & 12,2 & 11,8 & $>0,5$ & 4,058 \\
\hline gravidade especifica (g/L) & 1,0838 & 1,0838 & 1,0838 & 1,0826 & 0,36 & 0,104 \\
\hline
\end{tabular}

${ }^{1}$ Probabilidade. ${ }^{2}$ Coeficiente de variação. 
dietas contendo 850 e $1.000 \mathrm{mg}$ lisina digestível/kg de dieta.

Os níveis de lisina digestível estudados não influenciaram $(\mathrm{P}>0,05)$ a qualidade da casca (Tabela 6), mas poderiam influenciar o consumo de dieta e o suprimento de nutrientes para formação da casca do ovo. Novak et al. (2004) forneceram a poedeiras Dekalb Delta com 20 a 63 semanas de idade rações com 860 e 959 mg lisina total/kg e também não observaram diferenças na porcentagem de casca nem na gravidade específica dos ovos. Os resultados das análises de qualidade de casca obtidos neste estudo estão de acordo com relatos de Matos et al. (2009) em estudo no qual testaram os níveis de 700, 800 e 900 mg de lisina digestível/kg para poedeiras Lohmann LSL e de Schmidt et al. (2009) para poedeiras Lohmann Brown no período após muda forçada.

Apesar de os níveis de eletrólitos alterarem o equilíbrio hidroeletrolítico das mucosas intestinais (Sauveur \& Mongin, 1978), o aumento do nível de cloro, pela incorporação de lisina-HCl, não foi suficiente para ocasionar má absorção do íon-cálcio ou influenciar a formação da casca.

Não houve diferença $(\mathrm{P}>0,05)$ nas medidas bioquímicas sanguíneas (Tabela 7). Os resultados obtidos neste experimento estão de acordo com os valores de referência de Swenson (1996): glicose (130-270 mg/dL); ácido úrico (1-2 mg/dL); creatinina (1-2 mg/dL); albumina (1,6 a 2 g/dL); e proteína total (4-5 g/dL). Os níveis de proteína e de glicose no sangue (Tabela 7) foram diferentes dos reportados por Cunningham \& Morrison (1977), de 3,9 e 252 mg/100 mL de proteína e glicose no plasma sanguíneo de poedeiras de 20 semanas de idade.

Neste estudo, o valor médio de glicose plasmática variou de acordo com o estado metabólico da ave. A determinação da glicose em amostras de sangue é útil para avaliar o metabolismo de carboidratos. Para poedeiras Lohmann LSL sob suplementação com lisina digestível, Jardim Filho et al. (2008) não observaram diferença nos níveis sanguíneos de glicose (191,2 mg/dL) e de proteína $(3,8 \mathrm{mg} / \mathrm{dL})$.

Os níveis séricos de albumina (Tabela 7) diferiram dos obtidos por Cohen-Parsons et al. (1983), que utilizaram 10, 12 e 14\% PB para peruas em postura e verificaram efeito linear, com 3,1; 3,4 e 3,5 g albumina/dL, respectivamente. Jardim Filho et al. (2008) não observaram diferença para níveis de albumina para poedeiras Lohmann LSL alimentadas com rações com vários níveis de lisina digestível, cujo valor médio foi de 1,95 g/dL.

$\mathrm{Na}$ análise de acido úrico no soro (Tabela 7), não houve diferença $(\mathrm{P}>0,05)$ entre os níveis de lisina digestível testados. Os valores de ácido úrico para aves estão relacionados ao metabolismo renal e hepático e são a principal forma de excreção de bases nitrogenadas (Bell, 1971). Esse resultado indicou que os níveis de lisina testados não prejudicaram o equilíbrio aminoacídico. Os níveis plasmáticos de ácido úrico plasmático estão relacionados ao horário da alimentação das aves e os valores são mais elevados duas horas após a alimentação e reduzem ao máximo de 23,5 a 25 horas após a refeição em poedeiras leves e matrizes pesadas, respectivamente (Wilson \& Miles, 1988).

De acordo com as análises de creatinina (Tabela 7), não houve deficiência ou excesso de proteína, confirmando que as dietas foram isoproteicas e os níveis de lisina não alteraram o processo de absorção dos aminoácidos. A maior dosagem para creatinina na $34^{\mathrm{a}}$ semana ficou isolada apenas neste período avaliado.

As medidas do aparelho reprodutor (Tabela 8) não foram influenciadas pelos níveis de lisina da dieta, uma vez que os maiores níveis não aumentaram o peso das aves ( $\mathrm{P}>0,05)$, contrariando os resultados obtidos por Goulart (1997), que verificaram maior peso em galinhas arraçoadas com maior nível de lisina total. Harms \& Ivey (1993) avaliaram poedeiras submetidas a níveis de 0,627 a $0,833 \%$ de lisina total e de 13,79 a $16,68 \%$ de proteína durante de 26 a 34 semanas e observaram perda de peso de 21, 48, 53, 72, 79, 107 e $117 \mathrm{~g}$ em aves consumindo diariamente 754, 690, 648, 595,

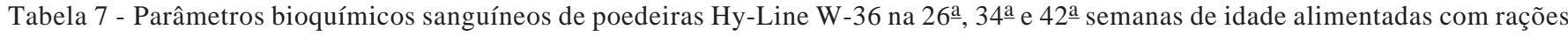
com diversos níveis de lisina digestível

\begin{tabular}{|c|c|c|c|c|c|c|c|c|c|c|}
\hline & \multicolumn{5}{|c|}{ Lisina (mg/kg) } & \multicolumn{4}{|c|}{ Semanas } & \multirow[t]{2}{*}{ CV (\%) } \\
\hline & 600 & 700 & 800 & 900 & $\mathrm{P}$ & 26 & 34 & 42 & $P$ & \\
\hline Glicose (mg/dL) & 175,2 & 190,7 & 193,7 & 180,0 & 0,35 & 188,0 & 186,1 & 180,5 & 0,74 & 10,69 \\
\hline Proteína (g/dL) & 3,4 & 3,7 & 3,5 & 3,3 & 0,36 & 3,5 & 3,5 & 3,4 & 0,77 & 11,46 \\
\hline Albumina (g/dL) & 1,9 & 1,8 & 1,8 & 1,9 & 0,81 & 1,7 & 1,9 & 2,0 & 0,13 & 12,22 \\
\hline Urato (mg/dL) & 2,1 & 1,6 & 1,9 & 1,8 & 0,60 & 1,8 & 1,7 & 2,1 & 0,43 & 36,67 \\
\hline Creatinina(mg/dL) & 0,6 & 0,7 & 0,8 & 0,7 & 0,04 & $0,6 b$ & $0,8 \mathrm{a}$ & $0,7 \mathrm{ab}$ & 0,007 & 14,48 \\
\hline
\end{tabular}

${ }^{1}$ Probabilidade, ${ }^{2}$ Coeficiente de variação.

Letras diferentes indicam diferença (5\%) pelo teste Tukey. 
Tabela 8 - Composição corporal e aparelho reprodutor de poedeiras Hy-Line W-36 alimentadas com rações com diversos níveis dietéticos de lisina digestível

\begin{tabular}{|c|c|c|c|c|c|c|c|c|c|c|}
\hline & \multicolumn{5}{|c|}{ Nível de lisina (mg/kg) } & \multicolumn{4}{|c|}{ Semanas } & \multirow[t]{2}{*}{$\mathrm{CV}(\%)$} \\
\hline & 600 & 700 & 800 & 900 & $\mathrm{P}$ & 26 & 34 & 42 & $\mathrm{P}$ & \\
\hline Peso ave (kg) & 1,33 & 1,32 & 1,35 & 1,37 & 0,89 & 1,37 & 1,29 & 1,37 & 0,40 & 9,79 \\
\hline Gordura abdominal (\%) & 2,51 & 3,11 & 3,36 & 3,18 & 0,59 & 3,60 & 2,42 & 3,09 & 0,15 & 36,76 \\
\hline Oviduto (\%) & 7,45 & 6,23 & 6,65 & 6,57 & 0,53 & 6,77 & 7,24 & 6,16 & 0,35 & 21,41 \\
\hline Ovário (\%) & 2,34 & 2,45 & 2,38 & 2,38 & 0,98 & 2,53 & 2,42 & 2,23 & 0,44 & 19,58 \\
\hline
\end{tabular}

560, 531 e 502 mg/lisina/ave, respectivamente. Os autores explicaram que a perda de peso foi evitada pela adição de lisina. Novak et al. (2004), no entanto, avaliaram níveis de lisina total (0,80 e 0,90\%) e aminoácidos sulfurados para poedeiras comerciais de 20 a 63 semanas de idade e constataram menor perda de peso na fase de 44 a 63 semanas de idade para as aves submetidas a $0,9 \%$ de lisina. No período total, o maior ganho de peso foi maior nas aves submetidas ao maior nível de lisina dietética total. Apesar de a lisina estar diretamente relacionada à síntese proteica, os maiores níveis de lisina digestível não aumentaram o peso da ave ou o percentual de aparelho reprodutor e ovário (Tabela 8).

\section{Conclusões}

O nível de lisina digestível de $600 \mathrm{mg} / \mathrm{kg}$ promove resultados satisfatórios de qualidade do ovo e desenvolvimento do aparelho reprodutor. O nível de lisina de $800 \mathrm{mg} / \mathrm{kg}$ de ração proporciona maior produção de ovos e o de $900 \mathrm{mg} / \mathrm{kg}$, melhores índices de conversão alimentar. O melhor aproveitamento de nitrogênio ocorre em níveis de 700 a 800 mg/kg e o de extrato etéreo, no nível de $700 \mathrm{mg} / \mathrm{kg}$.

\section{Agradecimentos}

Ao CNPq, Ajinomoto Biolatina e Granja Nossa Senhora Aparecida pelo apoio financeiro e material.

\section{Referências}

AGUilerA, H.D.N.; GONZALEZ, E.A.; PELAEZ, C.V. Determinacion de las necesidades de lisina en gallinas Leghorn en produccion. Mexico: CIFAP, 1990. v.3, p.274-283.

AL-SAFFAR, A.A.; ROSE, S.P. The response of laying hens to dietary amino acids. World's Poultry Science Journal, v.58, p.209-234, 2002.

AMERICAN EGG BOARD [2006]. Disponível em: <http:// www.aeb.org/EggProducts/resource.html>. Acesso em: 14/3/2006.

ANDRADE, L. Desempenho e qualidade dos ovos de poedeiras no primeiro e segundo ciclos de produção alimentadas com diferentes níveis de proteína bruta e aminoácidos na ração. 2004. 52f. Dissertação (Mestrado em Ciência Animal) - Universidade Federal de Goiás, Goiânia.
BAN, T. Estratégias nutricionais para atender a demanda por ovos de qualidade. In: SIMPÓSIO GOIANO DE AVICULTURA, 5., 2002, Goiânia. Anais... Goiânia: AGA-UFG, 2002. p.131-139.

BELL, D.J. Non-protein nitrogen and its fractions in plasma and erythrocytes. In: BELL, D.J., FREEMAN, B.M. (Eds.) Physiology and biochemistry of the domestic fowl. London: Academic Press, 1971. v.2. p.921-31.

BERTECHINI, A. G.; TEIXEIRA, A. S.; CEREZER, C. E. Níveis de lisina para poedeiras comerciais leves na fase de pico de postura. In: CONFERÊNCIA APINCO' DE CIÊNCIA E TECNOLOGIA, 1995, Campinas. Anais... Campinas: FACTA, 1995. p.75-76.

BOUYEH, M.; POURREZA, J.; SAME, A.H. Effects of different levels of lysine and protein on the performace of Hy Line layers. Journal of Science and Technology of Agriculture and Natural Resources, v.5, n.4, p.151-163, 2002.

BUSTANY, Z AL; ELWINGER, K. Response of laying hens to different dietary lysine intakes. Acta Agriculturae Scandinavica, v.7, p.27-40, 1987.

BUTLER, E.J. Plasma proteins. In: BELL, D.J., FREEMAN, B.M. (Eds.) Physiology and biochemistry of the domestic fowl. London: Academic Press, 1971. v.2. p.933-61.

CARVALHO, B.F. Desempenho, qualidade de ovos e balanço de nutrientes para poedeiras alimentadas com diferentes níveis de lisina e arginina digestíveis de 24 a 44 semanas de idade. 2006. 64f. Dissertação (Mestrado em Ciência Animal) - Universidade Federal de Goiás, Goiânia.

CHI, M.S.; SPEERS, G.M. Effect of force-feeding diets containing varying amounts of lysine on plasma free amino acids in laying hens. Poultry Science, v.55, p.1615-1626, 1977.

CORNELIUS, C.E. Liver function. In: KANEKO, J.J. Clinical biochemistry of domestic animals. 4.ed. San Diego: Academic Press, 1989. p.364-397.

COTTA, T. Reprodução da galinha e produção de ovos. Lavras: UFLA-FAEPE. 1997. 92p.

CUNNINGHAM, D.C.; MORRISON, W.D. Dietary energy and fat content as factors in the nutrition of developing egg strain pullets and young hens. 4.Effect on growth, hepatic lipogenic enzyme activity and body chemical composition of white le-horn pullets from hatch to 20 weeks of age. Poultry Science, v.56, p.1792-1805, 1977.

FARIA D.E.; HARMS, R.H.; RUSSELL, G.B. Threonine requirement of commercial laying hens a corn-soyabean meal diet. Poultry Science, v.81, n.6, p.809-814, 2002.

FLEMMING, J.S.; FLEMMING, R.; BONA FILHO, A. et al. Utilização de diferentes níveis de L-lisina na alimentação de poedeiras comerciais. Revista do Setor de Ciências Agrárias, v.1-2, p.115-119, 1991.

GOULART, C.C. Exigência nutricional de lisina para poedeiras leves e semipesadas. 1997. 51f. Dissertação (Mestrado em Zootecnia) - Universidade Federal de Viçosa, Viçosa, MG.

GOUS, R.M.; KLEYN, F.J. Response of laying hens to energy and amino acids. In: COLE, D.J.A.; HARESING, W. (Eds.) Recent developments in poultry nutrition. London: Butterworths, 1989. p.198-211. 
HARMS, R.H.; IVEY, F.J. Performance of commercial laying hens fed various supplemental amino acids in a corn-soybean meal diet. Journal of Applied Poultry Research, v.2, p.273-282, 1993.

HY LINE W-36. Manual de poedeira branca. Uberlândia: 2003. 29p.

JARDIM FILHO, R.M.; STRINGHINI, J.H.; ANDRADE, M.A. et al. Qualidade de ovos, parâmetros bioquímicos e desenvolvimento do aparelho reprodutor de poedeiras comerciais Lohmann LSL alimentadas com níveis crescentes de lisina digestível. Acta Scientiarum.Animal Sciences, v.30, p.25-31, 2008.

JENSEN, L.S.; CHANG, C.H.; FALEN, L. Response to lysine supplementation by laying hens fed practical diets. Poultry Science, v.53, p.1387-1391, 1974.

KARUNAJEEWA, H.; ABU-SEREWA, S.; THAM, S.H. et al. The effects of dietary level of sunflower seeds and lysine on egg quality and laying performance of White Leghorn hens. Journal Science of Food Agriculture, v.41, p.325-333, 1987.

KLASING, K.C. Amino acid. In: KlASING, K.C. (Ed.) Comparative avian nutrition. Wallingford: CAB International, 1998. p.133-170.

KOELKEBECK, K.W.; BAKER, D.H.; HAN, Y. et al. Effect of excess lysine, methionine, threonine, or tryptophan on production performance of laying hens. Poultry Science, v.70, p.1651-1653, 1991.

LARBIER, M.; LECLERCQ, B. Nutrition and feeding of poultry. Nottingham University Press: INRA, 1994. 305p.

MATOS, M.S.; LEANDRO, N.S.M.; CARVALHO, F.B. et al. Níveis de lisina e treonina digestíveis na ração de poedeiras comerciais sobre a qualidade de ovos. Acta Scientiarum.Animal Sciences, v.31, p.25-29, 2009.

MELUZZI, A.; SIRRI, F.; TALLARICO, N. et al. Nitrogen retention and performance of brown laying hens on diets with different protein content and constant concentration of amino acids and energy. British Poultry Science, v.42, p.213-217, 2001.

NAHM, K.H. Efficient feed nutrient utilization to reduce pollutants in poultry and swine manure. Critical Reviews in Environmental Science and Technology, v.32, n.1, p.1-16, 2002.

NOVAK, C.; YAKOUT, H.; SCHEIDELER, S. The combined effects of dietary lysine and total sulfur amino acid level on egg production parameters and egg components in Dekalb Delta laying hens. Poultry Science, v.83, p.977-984, 2004.

NOVAK, C.L.; SCHEIDELER, S.E. The combined effects of lysine and TSAA in two strains of laying hens. Poultry Science, v.77, p.1-180, 1998.

PATRICK, H.; SCHAIBLE, P.J. Poultry feeds \& nutrition. 2.ed. Uestport: AVI Publishing Company, 1980. 668p.

PROCHASKA, J.F.; CAREY, J.B.; SHAFER, D.J. The effect of L-lysine intake on egg component yield and composition in laying hens. Poultry Science, v.75, n.10, p.1268-1277, 1996.

RERAT, A. Absorption of nitrogen and amino acids from exogenous (fish meal proteins) or endogenous sources in the pig. Pig news and information, v.11, n.2, p.173-180, 1990.

RIZZO, M.F.; FARIA, D.E.; SILVA, F.H.A. et al. Avaliação das propriedades funcionais de ovos produzidos por poedeiras alimentadas com diferentes níveis de lisina e metionina. In:
CONFERÊNCIA APINCO' DE CIÊNCIA E TECNOLOGIA AVÍCOLAS, 2004, Santos. Trabalhos de Pesquisa... Santos: FACTA, 2004. p.26.

ROCHA, T.C.; GOMES, P.C.; DONZELE, J.L. et al. Níveis de lisina digestível em rações para poedeiras no período de 24 a 40 semanas de idade. Revista Brasileira de Zootecnia, v.38, n.9, p.1726-1731, 2009.

ROSTAGNO, H.S.; ALBINO, L.F.T.; DONZELLE, J.F. et al. Tabelas brasileiras para aves e suínos. Composição de alimentos e exigências nutricionais. 1.ed. Viçosa, MG: UFV, 2000. 141p.

SAUVEUR B.; MONGIN, P. Interrelationships between dietary concentrations of sodium, potassium and chloride in laying hens. British Poultry Science, v.19, n.4, p.475-485, 1978.

SCHEIDELER, S.E.; NOVAK, C.; SELL, J.L. et al. Hisex white leghorn lysine requirement for optimum body weight and egg production during early lay. Poultry Science, v.75, Suppl. 1, p.130, 1996.

SCHMIDT, M.; GOMES, P.C.; ROSTAGNO, H.S. et al. Exigência nutricional de lisina digestível para poedeiras semipesadas no segundo ciclo de produção. Revista Brasileira de Zootecnia, v.38, n.10, p.1956-1961, 2009.

SCHUTTE, J.B.; SMINK,W. Requirement of the laying hen for apparent fecal digestible lysine. Poultry Science, v.77, p.697-701, 1998.

SHAFER, D.J.; CAREY, J.B.; PROCHASKA, J.F. Effect of dietary methionine intake on egg component yield and composition. Poultry Science, v.75, n.9, p.1080-1085. 1996.

SHAFER, D.J.; CAREY, J.B.; PROCHASKA, J.F. et al. Dietary methionine intake effects on egg component yield, composition, functionality and texture analysis. Poultry Science, v.77, p.1056-1062. 1998.

SILVA, D.J.; QUEIROZ, A.C. Análise de alimentos: métodos químicos e biológicos. Viçosa, MG: UFV, 2002. p.235.

SOHAIL, S.S.; BRYANT, M.M.; ROLAND, S. Influence of supplemental lisina, isoleucina, treonina, triptofano and total sulfur amino acids on egg weight of Hy- Line W 36 hens. Poultry Science, v.81, n.6, p.1038-1044, 2002.

SOHAIL, S.S.; BRYANT, M.M.; ROLAND, SR.D.A. Influence of supplemental lysine on egg size and production of hens fed diets formulated based on lysine. Poultry Science, v.78, Suppl. 1, p.87, 1999.

SOHAIL, S.S.; ROLAND, SR.D.A. Partial explanation for difference in response of hens fed diets formulated based on protein vs lysine. Poultry Science, v.76, Suppl. 1, p.107, 1997.

STATISTICAL ANALYSIS SYSTEM - SAS ${ }^{\circledR}$ user's guide: statistics. Cary: SAS Institute, 2004.

SUMMERS, J.D. Reducing nitrogen excretion of the laying hen by feeding lower crude protein diets. Poultry Science, v.72, p.1473-1478, 1993.

SWENSON, M.J. Fisiologia dos animais domésticos. Circulação sanguínea e sistema cardiovascular. 11.ed. Rio de Janeiro: Guanabara, 1996. p.13-34.

UZU, G.; LARBIER, M. Lysine requirement in laying hens. Archiv für Geflügelkunde, v.49, n.4, p.146-150, 1985.

WILSON, H.R.; MILES, R.D. Research note: plasma uric of broiler breeder and leghorn male chickens: effect of feeding time. Poultry Science, v.67, p.345-347, 1988. 